\title{
Influence of reaction conditions on lignin hydrothermal treatment
}

\author{
Xabier Erdocia, Raquel Prado, M. Ángeles Corcuera and Jalel Labidi* \\ Chemical and Environmental Engineering Department, University of the Basque Country, San Seabastian, Spain
}

\section{Edited by:}

Arthur Ragauskas, Georgia Institute

of Technology, USA

Reviewed by:

Michelle J. Serapiglia, USDA-ARS

Eastern Regional Research Center,

USA

Yunqiao Pu, Georgia Institute of

Technology, USA

${ }^{*}$ Correspondence:

Jalel Labidi, Chemical and

Environmental Engineering

Department, University of the Basque

Country, Plaza Europa 1, San

Sebastián 20018, Spain

e-mail: jalel.labidi@ehu.es
Organosolv lignin, obtained from olive tree pruning under optimized conditions, was subjected to a hydrothermal depolymerization process catalyzed by sodium hydroxide. The depolymerization of lignin was carried out at $300^{\circ} \mathrm{C}$ using different reaction times $(20,40$, $60,70,80,90$, and $100 \mathrm{~min}$ ) in order to study the influence of this parameter on lignin depolymerization. The resulting products (oil and residual lignin) were measured and analyzed by different techniques (GC/MS, high-performance size-exclusion chromatography, and pyrolysis-GC/MS) in order to determine their nature and composition. Coke was also formed, at a lower quantity, uncompetitive repolymerization reactions during the lignin hydrothermal treatment. The maximum oil yield and concentration of monomeric phenolic compounds was obtained after $80 \mathrm{~min}$ of reaction time. The highest reaction time studied (100 $\mathrm{min}$ ) had the worst results with the lowest oil yield and highest coke production.

Keywords: lignin, depolymerization, homogeneous catalysis, organosolv

\section{INTRODUCTION}

Lignocellulosic biomass is said to be one of the most promising renewable raw materials since it can be transformed into a wide variety of products and by-products such as energy, materials, and chemicals. Lignocellulosic biomass is mainly composed of cellulose, hemicelluloses, and lignin. Among the main constituents of lignocellulosic biomass, lignin is one of the most interesting components since its aromatic nature and the broad variety of functional groups present in its chemical structure make it a unique and promising source of renewable products and commodity chemicals.

Lignin is primarily a structural material that adds strength and rigidity to cell walls and constitutes between 25 and $35 \%$ of the organic matter of woody plants (Kleinert and Barth, 2008). Lignin is an amorphous polyphenolic polymer composed principally of guaiacylpropane $(\mathrm{G})$, syringylpropane $(\mathrm{S})$, and p-hydroxyphenylpropane $(\mathrm{H})$ units that form a randomized structure in a three-dimensional network inside the cell wall (Faix, 1991). Carbon-carbon and carbon-oxygen bonds between monomers are found in lignin. However, $\beta-O-4$ aryl ether bonds are the most frequent dimeric linkages $(49-65 \%)$ probably due to the low steric hindrance at the $\beta$-carbon (Amen-Chen et al., 2001). The compositional ratios of these three units (H, G, S) can vary significantly with the feedstock. Guaiacylpropane is the predominant lignin monomer found in coniferous wood (softwoods) with minor amounts of $\mathrm{H}$ units. In hardwoods, $\mathrm{G}$ and $\mathrm{S}$ units are present in different ratios, but $S$ units are the most typical (Gosselink et al., 2010). All three units (H, G, S) are usually present in grass or herbaceous lignins (Buranov and Mazza, 2008).

In addition to being a structural material, a further role of lignin in the plant is to provide protection against microbial attacks and external agents. Lignin is interconnected by polysaccharides and helps to bind the cellulose/hemicelluloses matrix.
Lignin's amorphous structure provides flexibility to the mixture and confers impermeability.

Biomass pretreatment is an essential key for lignin valorization. There are several different treatments in which lignin is produced as a product or by-product. Lignin is considered as a by-product in the pulp and paper industries (i.e., kraft or lignosulfonate) and is usually burned to fulfill the energy needs of the process. However, lignin will also be produced in large amounts in the new biorefinery schemes (i.e., organosolv, steam explosion). In the case of organosolv treatments, different organic solvents, such as ethanol, can be employed. In addition, the existing organosolv processes use different conditions and degradation techniques - including various pressures, temperatures, solvents, and $\mathrm{pH}$ ranges - that uniquely modify the chemical structure and linkages of the lignin (Zakzeski et al., 2010).

Depolymerizing lignin to low-molecular-weight (LMW) aromatic and phenolic compounds likely offers the greatest opportunity to truly expand the spectrum of lignin applications (Zhang et al., 2011). Several studies have been performed in order to convert lignin to value-added products. In these studies, organosolv lignins have been found to be an appropriate raw material for producing LMW compounds (González Alriols et al., 2009). Among many thermochemical methods, base-catalyzed depolymerization (BCD) has been widely studied and has been shown to produce phenolic monomeric compounds (Thring, 1994; Miller et al., 1999, 2002; Nenkova et al., 2008; Yuan et al., 2010; Roberts et al., 2011). Thring (1994) studied the alkaline degradation of lignin by means of the combined effect of reaction time and temperature concluding that the identifiable monomeric products decreased with increasing severity of treatment, indicative of the increasing importance of pyrolytic and recondensation reactions occurring in the lignin structure under these conditions. In this work, the predominant identifiable liquid phenolic products were guaiacol 
and syringol at low severities and catechol and its derivatives at high severities.

Alkaline hydrolysis of Alcell $^{\circledR}$ lignin has also been studied by other authors (Miller et al., 1999, 2002). The reaction was enhanced by strong bases, and combinations of bases provided either positive synergistic effects, such as with $\mathrm{NaOH}$ and $\mathrm{Ca}(\mathrm{OH})_{2}$, or negative synergistic effects, such as with $\mathrm{LiOH}$ or $\mathrm{CsOH}$ with $\mathrm{Ca}(\mathrm{OH})_{2}$ (Miller et al., 1999). Model-compound studies indicated that the principle route for lignin depolymerization was through solvolysis of the ether linkages (Zakzeski et al., 2010). Several years later, BCD of lignin was carried out using water as the solvent (Miller et al., 2002). In this study, the authors observed that the base concentration was one of the most important factors governing lignin depolymerization. They found that a molar excess of a strong base $(\mathrm{NaOH})$ gave better results but also that a small amount of a strong base together with a larger amount of a less-expensive base $(\mathrm{CaO})$ produced good results.

In another study, it was shown that the optimal conditions required for lignin's transition were $180^{\circ} \mathrm{C}, 5 \% \mathrm{NaOH}$, a hydromodule of 1:10 and treatment duration of $6 \mathrm{~h}$ (Nenkova et al., 2008). Yuan et al. (2010) studied alkaline lignin degradation in hotcompressed water and ethanol. Alkaline lignin was successfully degraded into oligomers with $\mathrm{NaOH}$ as a catalyst in the presence of phenol as the capping agent. However, complete suppression of char formation could not be achieved.

In the most recent studies, Roberts et al. (2011) concluded that the formation of monomers is directly proportional to the concentration of sodium hydroxide in the aqueous medium. In addition, a mechanism for the $\mathrm{NaOH}$-catalyzed breakdown of the ether bonds of lignin was proposed. The preferential formation of derivatives of syringol can be explained by the stabilizing effect of the methoxy groups on the transition states of the carbenium ions. They also concluded that the production of monomers is limited by the oligomerization and polymerization reactions of the products formed.

The aim of this work was to study the influence of reaction time on the lignin depolymerization process. For this purpose, organosolv lignin samples were subjected to high temperatures and pressures with sodium hydroxide as a catalyst in an aqueous medium for different reaction times. The resulting products (oil and residual lignin) were measured and analyzed by different techniques [gas chromatography/mass spectrometry (GC/MS), high-performance size-exclusion chromatography (HPSEC), and pyrolysis (Py)-GC/MS] to determine the changes that occurred in both their nature and their quantity. Coke that was formed during a competitive repolymerization reaction was also measured.

\section{MATERIALS AND METHODS LIGNIN PRODUCTION}

Olive tree pruning (Olea eurpaea, variety Arróniz) was used as the raw material. Lignin was extracted from the raw material by an organosolv treatment consisting of ethanol-water $(70 \% \mathrm{w} / \mathrm{w})$ at $200^{\circ} \mathrm{C}$ for $90 \mathrm{~min}$ in a pressure reactor using previously optimized conditions (Toledano et al., 2011). The liquid fraction in which lignin was dissolved was separated from the solid fraction by filtration. Dissolved lignin was isolated by precipitation by adding two acidified water volumes ( $\mathrm{pH}$ around 2 ). The suspension was centrifuged at $4500 \mathrm{rpm}$ for $20 \mathrm{~min}$ to recover the lignin. After that, lignin was dried at $50^{\circ} \mathrm{C}$.

\section{BASE-CATALYZED DEPOLYMERIZATION}

The reactions were conducted in a stirred batch reactor (5500 Parr reactor) with a 4848 Reactor controller. The volume of the reactor vessel was $100 \mathrm{~mL}$. The reaction conditions were $300^{\circ} \mathrm{C}$ reaching pressures of about $9 \mathrm{MPa}$. The lignin:solvent (water) ratio was 1:20 $(\mathrm{w} / \mathrm{w})$. The catalyst (sodium hydroxide) concentration was set at $4 \%$ (w/w) (Toledano et al., 2014). The reaction conditions were chosen considering the reactor limitations, our previous experience, and the conditions reported in the literature (Thring, 1994; Roberts et al., 2011; Toledano et al., 2012). Three experiments were carried out, each using the reaction times $20,40,60,70,80$, 90 , and $100 \mathrm{~min}$.

\section{PRODUCT SEPARATION PROCESS}

The liquid solution recovered after the reaction time in the batch microreactor was treated in order to separate the products. Firstly, $\mathrm{HCl}$ at $37 \%$ was added until $\mathrm{pH} 1$ was reached. In this way, residual lignin and coke precipitated and were separated from the liquid by filtration using MN $640 \mathrm{w}$ filters and washed with acidified water (water at $\mathrm{pH} 1$ with $\mathrm{HCl}$ as the acidic agent) to remove residual liquid.

This liquid fraction was subjected to a liquid-liquid extraction process with ethyl acetate. Anhydrous sodium sulfate was added to the obtained organic phase in order to remove the traces of water and then it was filtrated to remove the added sodium sulfate. Then, this organic phase was vacuum evaporated at $0.02 \mathrm{MPa}$ in order to obtain oil with the depolymerized products.

The solid phase was washed with tetrahydrofuran (THF) and was stirred for $3 \mathrm{~h}$ in a beaker. The THF solution was filtrated, and the undissolved solid (coke) was oven-dried at $50^{\circ} \mathrm{C}$. The THF solution was vacuum evaporated to recover the unconverted lignin (Toledano et al., 2014).

\section{ANALYSIS OF THE DEPOLYMERIZATION PRODUCTS}

Oil was characterized in order to establish the nature of the monomeric phenolic compound. The oil was dissolved in HPLCgrade ethyl acetate in a metric flask. The solution was injected into a GC (7890A)-MS (5975C inert MSD with Triple-Axis Detector) Agilent equipped with a capillary column HP-5MS [(5\%-phenyl)-methylpolysiloxane, $60 \mathrm{~m} \times 0.25 \mathrm{~mm}$ ]. The temperature program started at $50^{\circ} \mathrm{C}$ and then the temperature was raised to $120^{\circ} \mathrm{C}$ at $10^{\circ} \mathrm{C} / \mathrm{min}$, held for $5 \mathrm{~min}$, raised to $280^{\circ} \mathrm{C}$ at $10^{\circ} \mathrm{C} / \mathrm{min}$, held for $8 \mathrm{~min}$, raised to $300^{\circ} \mathrm{C}$ at $10^{\circ} \mathrm{C} / \mathrm{min}$, and held for $2 \mathrm{~min}$. Helium was used as the carrier gas. Calibration was done using pure compounds obtained from Sigma-Aldrich: phenol, $o$ cresol, $m$-cresol, $p$-cresol, guaiacol, catechol, 3-methylcatechol, 4methylcatechol, 4-ethylcatechol, 3-methoxycatechol, syringol, 4hydroxybenzaldehyde, acetovanillone, veratrol, 4-hydroxybenzoic acid, 4-hydroxy-3-methoxyphenylacetone, vanillin, vanillic acid, syringaldehyde, 3,5-dimethoxy-4-hydroxyacetophenone, syringic acid, and ferulic acid (Erdocia et al., 2012).

Residual lignin was subjected to HPSEC to evaluate lignin molecular weight (MW) and molecular weight distribution (MWD) using a JASCO instrument equipped with an interface (LCNetII/ADC) and a refractive index detector (RI-2031Plus). Two 
PolarGel-M columns $(300 \mathrm{~mm} \times 7.5 \mathrm{~mm})$ and PolarGel-M guard $(50 \mathrm{~mm} \times 7.5 \mathrm{~mm})$ were employed. Dimethylformamide solution containing $0.1 \%$ lithium bromide was used as the solvent. The flow rate was $0.7 \mathrm{~mL} / \mathrm{min}$, and the analyses were carried out at $40^{\circ} \mathrm{C}$. Calibration was made using polystyrene standards (SigmaAldrich) ranging from 266 to 70,000 g/mol (Erdocia et al., 2012).

In order to elucidate the changes produced in the structure of residual lignin with respect to the raw lignin, Py-GC/MS analysis was performed. The pyrolysis was carried out using a CDS analytical Pyroprobe 5150. The pyrolysis temperature was set at $400^{\circ} \mathrm{C}$ for $15 \mathrm{~s}$ with a heating rate of $2^{\circ} \mathrm{C} / \mathrm{ms}$. Then, the products were analyzed by the GC-MS instrument described above. The oven program started at $50^{\circ} \mathrm{C}$ and was held for $2 \mathrm{~min}$ at this temperature, after which the temperature was raised to $120^{\circ} \mathrm{C}$ at $10^{\circ} \mathrm{C} / \mathrm{min}$ and held for $5 \mathrm{~min}$, raised to $280^{\circ} \mathrm{C}$ at $10^{\circ} \mathrm{C} / \mathrm{min}$, held for $8 \mathrm{~min}$, and finally raised to $300^{\circ} \mathrm{C}$ at $10^{\circ} \mathrm{C} / \mathrm{min}$ and held for $10 \mathrm{~min}$.

\section{RESULTS AND DISCUSSION OLIVE TREE PRUNING LIGNIN CHARACTERIZATION}

Organosolv olive tree pruning lignin presented the following composition: acid-insoluble lignin $71.90 \pm 0.79 \%$, acid-soluble lignin $1.63 \pm 0.08 \%$, total sugars $2.94 \pm 0.14 \%$ (glucose $1.75 \pm 0.12 \%$, xylose $1.10 \pm 0.03 \%$, and arabinose $0.09 \pm 0.01 \%$ ), and ash content $0.39 \pm 0.01 \%$.

\section{YIELD OF DEPOLYMERIZED PRODUCTS}

Three main products were obtained after lignin depolymerization at any reaction time: oil, residual lignin, and coke. The obtained data were statistically analyzed and according to Table 1, all product yield values (oil, residual lignin, and coke) were significant for time factor $(p<0.05)$.

In Figure $\mathbf{1}$ are presented the yields of the products obtained after base catalyzed depolymerization of the lignin at different reaction times. Regarding the oil yield, $80 \mathrm{~min}$ gave the best result for oil production $(22.28 \pm 0.37 \%)$ while the maximum time studied $(100 \mathrm{~min})$ presented the lowest yield of the desired product $(16.57 \pm 0.40 \%)$. These results are in agreement with other studies that showed that increasing the reaction severity decreases the concentration of monomeric compounds (oil production) as the importance of pyrolytic and recondensation reactions are enhanced (Miller et al., 1999). As can be observed, oil yield increased with the reaction time until reaching a maximum at $80 \mathrm{~min}$ and then decreased dramatically because of the recondensation reactions occurring at longer reaction times.

The residual lignin yield showed an opposite trend. At $20 \mathrm{~min}$ of reaction time, residual lignin was the main product $(40 \%$ of the original amount of lignin). As the reaction time increased, this residual lignin decreased to a value of $30 \%$ of the initial lignin concentration, which remained almost constant after $60 \mathrm{~min}$ of reaction time. The increase of reaction time did not affect the residual lignin yield, which means that at high severities (more than 60 min of reaction time) the reactions taking place only affected oil production (hydrolysis and demethoxylation reactions) or coke production (pyrolytic and recondensation reactions).

Regarding coke production, it had a different behavior from the oil or residual lignin. Its production increased with reaction time but then decreased at 70 and $80 \mathrm{~min}(7.65 \pm 0.30$ and
Table 1 | Summary of the one-way ANOVA analysis for the oil, residual lignin, and coke yields with reaction time as factor.

\begin{tabular}{lllrcrl}
\hline $\begin{array}{l}\text { Dependent } \\
\text { variable }\end{array}$ & Source & SS & df & MS & $\boldsymbol{F}$ & $\boldsymbol{p}$-Value \\
\hline Oil & Time & 74.1798 & 6 & 12.3633 & $88.60^{*}$ & $<0.0001$ \\
& Residual & 1.95352 & 14 & 0.13953 & & \\
& Total & 76.1333 & 20 & & & \\
Residual lignin & Time & 310.183 & 6 & 51.6971 & $638.85^{*}$ & $<0.0001$ \\
& Residual & 1.13292 & 14 & 0.08092 & & \\
& Total & 311.316 & 20 & & & \\
Coke & Time & 183.815 & 6 & 30.6359 & $443.82^{*}$ & $<0.0001$ \\
& Residual & 0.966389 & 14 & 0.06902 & & \\
& Total & 184.782 & 20 & & & \\
\hline
\end{tabular}

$S S$, sum of squares; $d f$, degrees of freedom; MS, mean square; $F$, calculated value of $F$ * Significant at $5 \%$ of probability of error.

$6.04 \pm 0.25 \%$, respectively) and for the last two reaction times it increased again and produced the highest values. This behavior has already been reported by other authors who claimed that char formation from lignin in aqueous media was promoted by long reaction times (Yokoyama et al., 1998).

The yields of depolymerized products showed that, at 70 and $80 \mathrm{~min}$ reaction times, the main reactions were hydrolysis and demethoxylation reactions, and so oil yield increased and coke production decreased. However, at longer reaction times, depolymerization reactions were not as significant as pyrolytic or recondensation reactions, and so coke production was maximal.

\section{OIL CHARACTERIZATION}

The characterization of the oil obtained in different depolymerization reactions by GC-MS showed differences in the concentration of the obtained phenolic compounds but not in their nature. In all cases, the same compounds were produced but in different quantities as can be observed in Table 2. Among the different linkages present in the lignin structure, $\beta-O-4$ is said to be the first to be cleaved during hydrothermal degradation of lignin (Li et al., 2007). Roberts et al. (2011) stated that the cleavage of the $\beta$-O-4 ether bond takes place heterolytically via the formation of a sodium phenolate derivative and a carbenium-ion-like transition state, which is instantly neutralized by a hydroxide ion. The sodium cations catalyze the reaction by forming cation adducts with lignin and, thus, polarizing the ether bond. These findings suggest that the polarization of the base is a key step and will govern the kinetics and the mechanism followed in the depolymerization reaction. This is the main reason that makes the nature of phenolic compounds obtained in all experiments to be the same as the employed catalyst was $\mathrm{NaOH}$ in all cases.

The main products present in the oil were catechol and its derivatives: 3-methylcatechol, 4-methylcatechol, and 4-ethylcatechol. Concentrations of these products increased with reaction time (severity) until $80 \mathrm{~min}$. High severities promoted the production of phenol, cresols, and catechol (Wahyudiono et al., 2007) but at very high severities, the concentration of monomeric compounds decreased (Thring, 1994). This was also observed here in the 


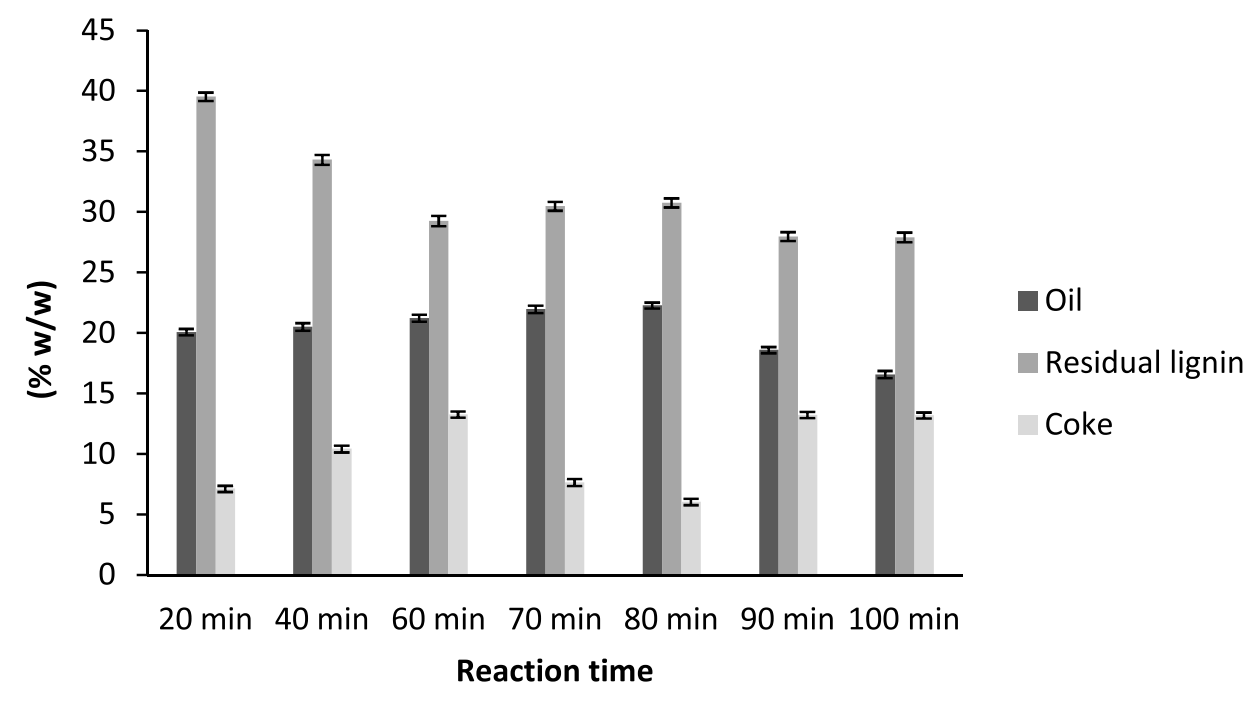

FIGURE 1 |Yields of the products obtained after base-catalyzed depolymerization of lignin at different reaction times.

Table 2 | Phenolic monomers concentration in the oil analyzed by GC-MS (\% w/w).

\begin{tabular}{|c|c|c|c|c|c|c|c|}
\hline Compound & $20 \mathrm{~min}$ & $40 \mathrm{~min}$ & $60 \mathrm{~min}$ & $70 \mathrm{~min}$ & $80 \mathrm{~min}$ & $90 \mathrm{~min}$ & $100 \mathrm{~min}$ \\
\hline Cresols & $0.48 \pm 0.04$ & $0.16 \pm 0.02$ & $0.22 \pm 0.03$ & $0.35 \pm 0.03$ & $0.36 \pm 0.02$ & $0.37 \pm 0.03$ & $0.35 \pm 0.02$ \\
\hline Catechol & $1.90 \pm 0.23$ & $3.84 \pm 0.34$ & $4.53 \pm 0.41$ & $3.54 \pm 0.39$ & $6.78 \pm 0.52$ & $2.84 \pm 0.31$ & $2.84 \pm 0.34$ \\
\hline 3-Methylcatechol & N.D. & $1.18 \pm 0.20$ & $1.93 \pm 0.31$ & $2.20 \pm 0.30$ & $2.96 \pm 0.38$ & $1.73 \pm 0.18$ & $1.98 \pm 0.23$ \\
\hline 4-Methylcatechol & $0.26 \pm 0.05$ & $2.46 \pm 023$ & $3.61 \pm 0.35$ & $3.40 \pm 0.30$ & $5.37 \pm 0.46$ & $2.55 \pm 0.20$ & $2.93 \pm 0.28$ \\
\hline 4-Hydroxybenzaldehyde & N.D. & N.D. & $0.39 \pm 0.02$ & $0.44 \pm 0.03$ & $0.58 \pm 0.04$ & $0.31 \pm 0.02$ & $0.37 \pm 0.02$ \\
\hline 4-Hydroxy-3-phenylacetone & N.D. & N.D. & $0.04 \pm 0.00$ & $0.06 \pm 0.01$ & $0.07 \pm 0.00$ & $0.06 \pm 0.01$ & $0.03 \pm 0.00$ \\
\hline
\end{tabular}

experiments with highest severities (90 and $100 \mathrm{~min}$ ), the concentration of phenolic monomeric compounds dropped compared to shorter reaction times.

\section{RESIDUAL LIGNIN}

The changes produced in the residual lignins were analyzed by HPSEC with the raw lignin as a reference. As can be observed in Figure 2, all the residual lignins had two main peaks: one related to a fraction with higher MW than raw lignin and the other one related to a lower MW fraction. The first peak of the experiments appeared earlier than the raw lignin main peak, meaning higher MW fractions. The reason for this behavior was the polymerization reactions that have been reported by other authors (Yuan et al., 2010) occurring between unstable lignin fragments and the original lignin producing unconverted lignin with higher MW than the initial lignin. Repolymerization phenomena affected all samples regardless of the applied severity parameter. Alkaline condensations typically involve the activation of the unsubstituted aromatic C-5 position. Formaldehyde, formed as a by-product of the cleavage of the $C \gamma$, may participate in the reaction (Valenzuela, 2011).

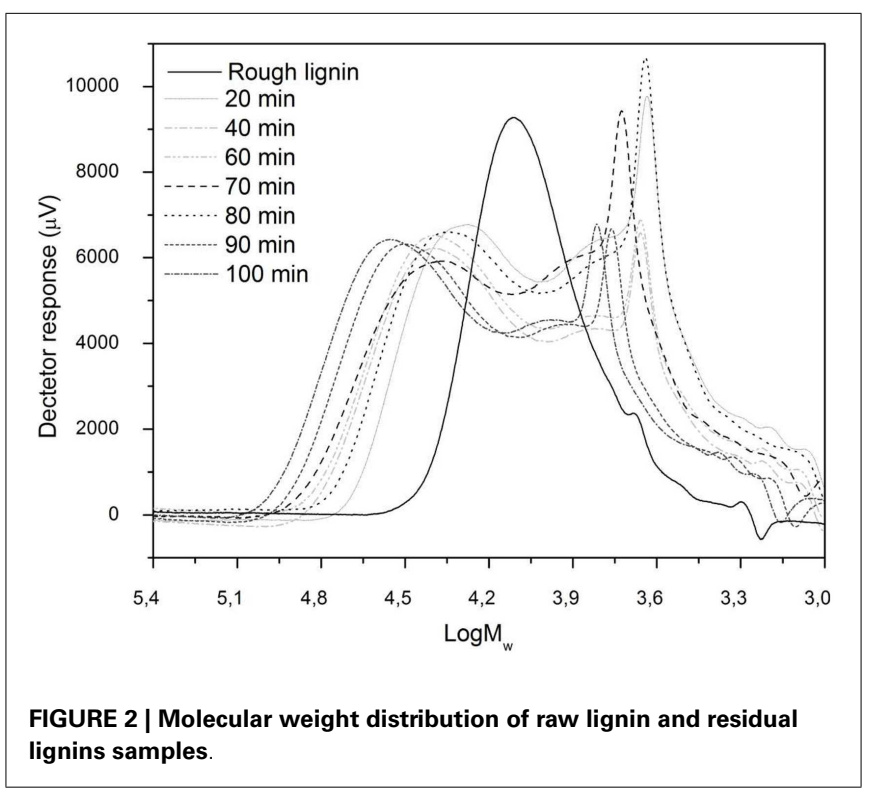



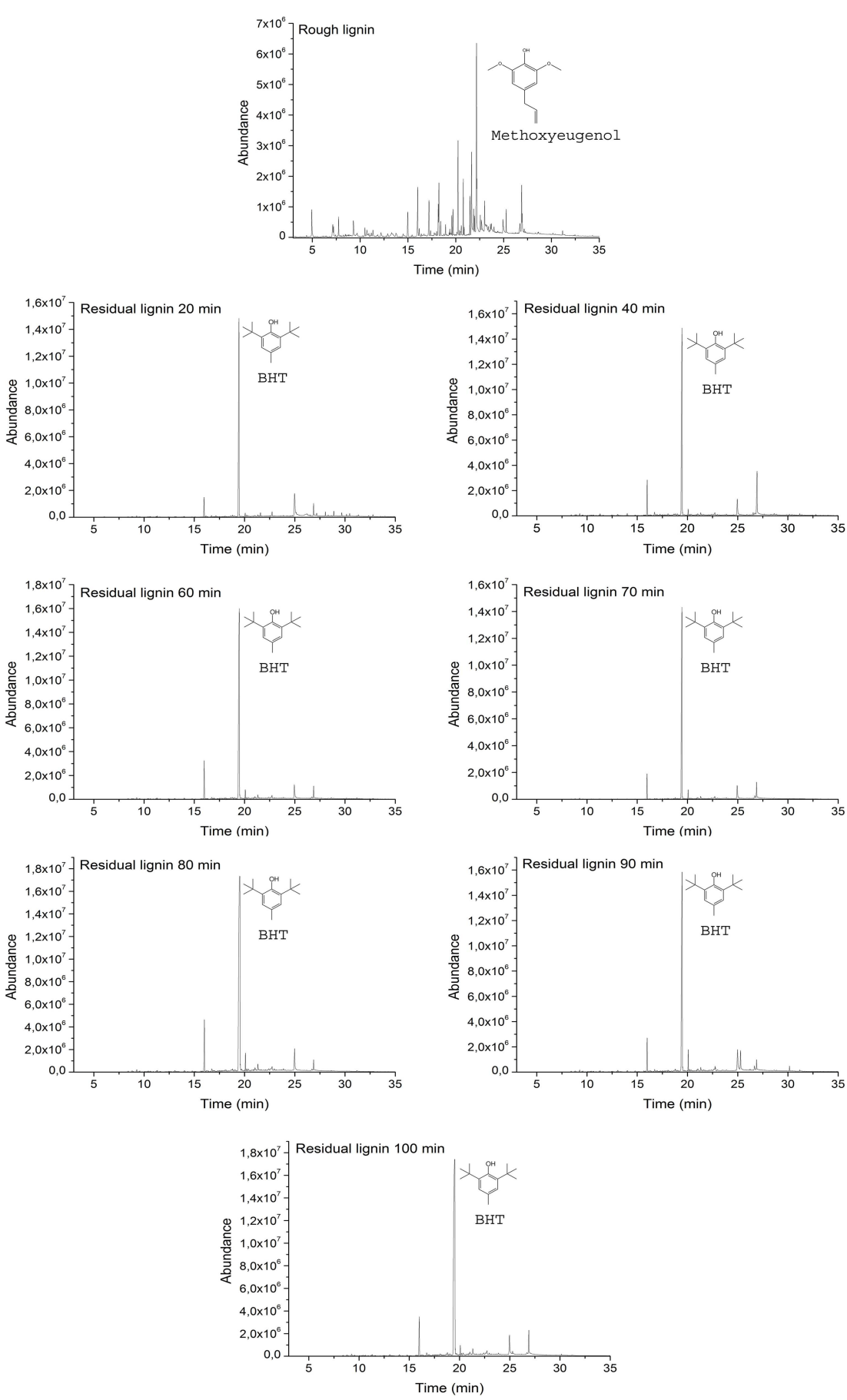

FIGURE 3 | Chromatograms of raw and residual lignins pyrolysis.

However, residual lignin from experiments at 90 and $100 \mathrm{~min}$ presented the highest MW repolymerized fractions, which indicate that higher reaction times enhanced repolymerization reactions (Yuan et al., 2010).

Peaks associated with lower MW lignin fractions than the raw lignin could also be observed in all reaction mixtures containing residual lignin. These peaks show that depolymerization reactions occurred during the hydrothermal treatment of the lignin. In this case, after $80 \mathrm{~min}$ reaction time, residual lignin was the main fraction of the lowest MW peak, which means that, at this reaction time, depolymerization of lignin was enhanced. This is in agreement with the results discussed above in which the 80 min reaction time gave the highest yield of depolymerized products. 
Residual lignin was also subjected to Py-GC/MS in order to analyze the changes in its nature and structure. As can be seen in Figure 3, raw lignin and all residual lignins were subjected to this method. Chromatograms of all residual lignins presented the same pattern, which indicates that the structure of all residual lignins was the same. This behavior also indicates that the mechanism that formed this residual lignin was identical in all the experiments regardless of the time employed for the reaction. Furthermore, this fact confirmed that the base concentration and its nature are the main factors governing depolymerization of lignin (Miller et al., 2002; Toledano et al., 2012).

The differences between the raw lignin and the residual lignins confirmed that residual lignins were not unconverted lignins they were new lignins created by repolymerization reactions that occurred between unstable fragments and depolymerization reactions of raw lignin. Figure 3 shows that the main peak in all residual lignin samples at $19.45 \mathrm{~min}$ was related to butylated hydroxytoluene while, in the raw lignin, this peak did not appear. Butylated hydroxytoluene occupied more than $65 \%$ of the area of the chromatograms of residual lignin. Other main compounds from residual lignin pyrolysis, but in lower quantity, were 2-tert-butyl- $p$-cresol and $n$-hexadecanoic acid.

The chromatogram of raw lignin was more heterogeneous than the chromatograms of residual lignins. Several compounds were obtained after the pyrolysis of the lignin sample and all of them were different from those obtained from the residual lignins. The main compound appeared at $22.18 \mathrm{~min}$ and was related to methoxyeugenol, which represented only $16.7 \%$ of the total area of the chromatogram. Other compounds obtained in a significant quantity were vanillin, eugenol, acetophenone, 4-hydroxy-3,5-dimethoxy-benzaldehyde, and octadecanoic acid.

\section{CONCLUSION}

The influence of reaction time on the lignin depolymerization process was studied in this work. The best results in terms of phenolic monomeric compounds production were found for $80 \mathrm{~min}$ of reaction time. At this time, coke production was also minimized, and the residual lignin MW was lowest. It was also concluded that, at highest reaction times, coke production and the MW of residual lignin increased because of pyrolytic and recondensation reactions. Moreover, the production of phenolic monomeric compounds dropped dramatically at the longest reaction times. It can also be concluded that the reaction time did not affect the reaction mechanism as all the obtained products were of the same nature and the structure of residual lignin was the same in all cases.

\section{ACKNOWLEDGMENTS}

Authors would like to thank the Department of Education, Universities and Investigation, and Department of Agriculture, Fishing and Food of the Basque Government (scholarship of young researchers training and project IT672-13) for financially supporting this work.

\section{REFERENCES}

Amen-Chen, C., Pakdel, H., and Roy, C. (2001). Production of monomeric phenols by thermochemical conversion of biomass: a review. Bioresour. Technol. 79, 277-299. doi:10.1016/S0960-8524(00)00180-2
Buranov, A. U., and Mazza, G. (2008). Lignin in straw of herbaceous crops. Ind. Crops Prod. 28, 237-259. doi:10.1016/j.indcrop.2008.03.008

Erdocia, X., Toledano, A., Corcuera, M. A., and Labidi, J. (2012). Organosolv black liquor hydrolysis to obtain low molecular weight phenolic compounds. Chem. Eng. Trans. 29, 535-540. doi:10.3303/CET1229090

Faix, O. (1991). Classification of lignins from different botanical origins by FT-IR spectroscopy. Holzforschung 45, 21-27. doi:10.1515/hfsg.1991.45.s1.21

González Alriols, M., Tejado, A., Blanco, M., Mondragon, I., and Labidi, J. (2009). Agricultural palm oil tree residues as raw material for cellulose, lignin and hemicelluloses production by ethylene glycol pulping process. Chem. Eng. J. 148, 106-114. doi:10.1016/j.cej.2008.08.008

Gosselink, R. J. A., van Dam, J. E. G., de Jong, E., Scott, E. L., Sanders, J. P. M., Li, J., et al. (2010). Fractionation, analysis, and PCA modeling of properties of four technical lignins for prediction of their application potential in binders. Holzforschung 64, 193-200. doi:10.1515/hf.2010.023

Kleinert, M., and Barth, T. (2008). Phenols from lignin. Chem. Eng. Technol. 31, 736-745. doi:10.1002/ceat.200800073

Li, J., Henriksson, G., and Gellerstedt, G. (2007). Lignin depolymerization/repolymerization and its critical role for delignification of aspen wood by steam explosion. Bioresour. Technol. 98, 3061-3068. doi:10.1016/j.biortech.2006. 10.018

Miller, J. E., Evans, L., Littlewolf, A., and Trudell, D. E. (1999). Batch microreactor studies of lignin and lignin model compound depolymerization by bases in alcohol solvents. Fuel 78, 1363-1366. doi:10.1016/S0016-2361(99) 00072-1

Miller, J. E., Evans, L. R., Mudd, J. E., and Brown, K. A. (2002). Batch Microreactor Studies of Lignin Depolymerization by Bases. 2. Aqueous Solvents. Albuquerque, New Mexico: Sandia National Laboratories, Report SAND2002-1318.

Nenkova, S., Vasileva, T., and Stanulov, K. (2008). Production of low molecular phenolic compounds from technical hydrolysis lignin and wood biomass. Chem. Nat. Comp. 44, 182-185. doi:10.1007/s10600-008-9009-z

Roberts, V. M., Stein, V., Reiner, T., Lemonidou, A., Li, X., and Lercher, J. A. (2011). Towards quantitative catalytic lignin depolymerization. Chemistry 17, 5939-5948. doi:10.1002/chem.201002438

Thring, R. W. (1994). Alkaline degradation of ALCELL ${ }^{\circledR}$ lignin. Biomass Bioenergy 7, 125-130. doi:10.1016/0961-9534(94)00051-T

Toledano, A., Serrano, L., and Labidi, J. (2011). Enhancement of lignin production from olive tree pruning integrated in a green biorefinery. Ind. Eng. Chem. Res. 50, 6573-6579. doi:10.1021/ie102142f

Toledano, A., Serrano, L., and Labidi, J. (2012). Organosolv lignin depolymerization with different base catalysts. J. Chem. Technol. Biotechnol. 87, 1593-1599. doi:10.1002/jctb.3799

Toledano, A., Serrano, L., and Labidi, J. (2014). Improving base catalyzed lignin depolymerization by avoiding lignin repolymerization. Fuel 116, 617-624. doi:10.1016/j.fuel.2013.08.071

Valenzuela, M. (2011). Base-Catalyzed Depolymerization of Lignin and Hydrodeoxygenation of Lignin Model Compounds for Alternative Fuel Production. Ph.D. thesis, Atlanta: Georgia Institute of Technology.

Wahyudiono, Kanetake, T., Sasaki, M., and Goto, M. (2007). Decomposition of a lignin model compound under hydrothermal conditions. Chem. Eng. Technol. 30, 1113-1122. doi:10.1002/ceat.200700066

Yokoyama, C., Nishi, K., Nakajima, A., and Seino, K. (1998). Thermolysis of organosolv lignin in supercritical water and supercritical methanol. J. Jpn. Petrol. Inst. 41, 243-250. doi:10.1627/jpi1958.41.243

Yuan, Y., Cheng, S., Leitch, M., and Xu, C. (2010). Hydrolytic degradation of alkaline lignin in hot-compressed water and ethanol. Bioresour. Technol. 101, 9308-9313. doi:10.1016/j.biortech.2010.06.140

Zakzeski, J., Bruijnincx, P. C. A., Jongerius, A. L., and Weckhuysen, B. M. (2010). The catalytic valorization of lignin for the production of renewable. Chem. Rev. 110, 3552-3599. doi:10.1021/cr900354u

Zhang, X., Tu, M., and Paice, M. G. (2011). Routes to potential bioproducts from lignocellulosic biomass lignin and hemicelluloses. Bioenergy Res. 4, 246-257. doi:10.1007/s12155-011-9147-1

Conflict of Interest Statement: The authors declare that the research was conducted in the absence of any commercial or financial relationships that could be construed as a potential conflict of interest. 
Received: 30 December 2013; accepted: 19 March 2014; published online: 01 April 2014. Citation: Erdocia X, Prado R, Corcuera MÁ and Labidi J (2014) Influence of reaction conditions on lignin hydrothermal treatment. Front. Energy Res. 2:13. doi: 10.3389/fenrg.2014.00013

This article was submitted to Bioenergy and Biofuels, a section of the journal Frontiers in Energy Research.
Copyright (c) 2014 Erdocia, Prado, Corcuera and Labidi. This is an open-access article distributed under the terms of the Creative Commons Attribution License (CC BY). The use, distribution or reproduction in other forums is permitted, provided the original author(s) or licensor are credited and that the original publication in this journal is cited, in accordance with accepted academic practice. No use, distribution or reproduction is permitted which does not comply with these terms. 